\title{
MISTURAS MÚLTIPLAS NA SUPLEMENTAÇÃO DE OVINOS: CARACTERISTICAS DA CARCAÇA E RENDIMENTOS DE CORTES COMERCIAIS ${ }^{1}$
}

\author{
Pablo Teixeira Leal de Oliveira ${ }^{2}$, Gherman Garcia Leal de Araújo ${ }^{3}$, Tadeu Vinhas Voltolini ${ }^{3}$, Salete Alves \\ de Moraes $^{3}$, Luiz Gustavo Ribeiro Pereira ${ }^{3}$, Daniel Ribeiro Menezes ${ }^{6}$ \\ ${ }^{1}$ Pesquisa financiada FUNDECI-ETENE \\ ${ }^{2}$ Mestrando do Programa de Pós-graduação em Ciência Animal - UNIVASF/Petrolina-PE. Bolsista FACEPE. e-mail: \\ pablolea14@hotmail.com \\ ${ }^{3}$ Pesquisador da Embrapa Semi-Árido, Petrolina/PE. \\ ${ }^{6}$ Doutorando do programa de Pós-graduação em Zootecnia - UFPB/Areia-PB.
}

Resumo: O objetivo do presente estudo foi avaliar os parâmetros de carcaça e rendimentos de cortes comerciais de ovinos mantidos em pastagens diferidas de capim Bufel recebendo suplementos múltiplos com diferentes teores de uréia. Os tratamentos avaliados foram: 5, 8, 11 e 14\% de uréia na matéria seca do suplemento. Foram utilizados 36 ovinos machos, nove animais por tratamento, com peso corporal inicial médio de $18 \mathrm{~kg}$, distribuídos em quatro grupos. O delineamento experimental adotado foi o inteiramente casualizado com nove repetições por tratamento. Os teores de uréia no concentrado não influenciaram $(\mathrm{P}>0,05)$ os pesos e rendimentos de carcaça quente e fria e os pesos e rendimentos de cortes cárneos comerciais (pernil, paleta, costela e carré). O teor de uréia a ser utilizado no concentrado para ovinos mantidos em pastagens diferidas de capim Bufel estará condicionado ao desempenho econômico proporcionado pelo suplemento.

Palavras-chave: capim Bufel, Cenchrus ciliares, diferimento de pastagens, suplementação protéica, teores de uréia

\section{MULTIPLE SUPPLEMENTATION FOR SHEEP: CARCASS TRAITS AND COMMERCIAL MEAT CUTS INCOMES}

\begin{abstract}
The objective of present trial was to evaluate the carcass traits and weight and incomes of commercial meat cuts of sheep grazing differed Bufel grass pasture receiving multiple supplementation contained different urea levels. The treatments evaluated were: $5,8,11 \mathrm{e} 14 \%$ levels of urea in supplement. There were used 36 male sheep, nine animals by treatments, with $18 \mathrm{~kg}$ of initial live weight, distributed in four groups. The experimental design adopted was a completely randomized with nine replicates by treatments. The levels of urea in supplement did not influence $(\mathrm{P}>0.05)$ weight and incomes of hot and cold carcass and weight and incomes of commercial meat cuts (leg, shoulder, rib and briscket). The use of urea in supplement concentrate for grazing sheep in differed Bufel grass will be conditioned to economical performance promoted by each supplement.
\end{abstract}

Keywords: Bufel grass, Cenchrus ciliares, differed pastures, protein supplementation, urea levels

\section{Introdução}

O potencial produtivo das forrageiras tropicais é reconhecido em diversos trabalhos, porém são poucos os relatos de sistemas eficientes e, no geral, a produtividade animal é baixa. Nos trópicos, a natureza extensiva da produção animal se caracteriza por pouco ou nenhum controle sobre o processo de pastejo (Silva, 2004).

A produção em pastagem de ovinos tem estimulado a formulação de suplementos com fontes alternativas regionais mais baratas, que possam viabilizar a obtenção de ganhos diários de peso, que podem ser decisivos para o sucesso da atividade.

Ovinos mantidos em pastejo durante o período seco do ano apresentam baixo desempenho, em decorrência da limitação qualitativa e quantitativa das pastagens. No período seco do ano, as forragens apresentam baixo valor nutritivo não suprindo as exigências em proteína degradada no rúmen (PDR) para crescimento microbiano e atividade fermentativa adequada (Dove, 1996). Conseqüentemente, a taxa de digestão da parede celular cai abruptamente e a forragem deixa o rúmen mais lentamente, com consequente redução no consumo.

Nessas situações, a correção da deficiência protéica da pastagem via suplementação, para estímulo ao consumo e à digestibilidade da forragem seca, melhorando o desempenho dos animais, além de, 
promover alterações nos parâmetros qualitativos e quantitativos da carcaça e no rendimento de cortes cárneos pode ser estratégia técnica viável. Desse modo, o objetivo do presente trabalho foi avaliar os parâmetros de carcaça e os rendimentos de cortes comercias da carcaça de ovinos mantidos em pastagens diferidas de capim Bufel recebendo suplementação múltipla contendo diferentes teores de uréia.

\section{Material e Métodos}

O ensaio foi conduzido no Campo Experimental da Caatinga pertencente a Embrapa Semi-Árido, em Petrolina-PE. Foram comparados quatro teores de uréia no suplemento concentrado, sendo 5; 8; 11 e $14 \%$ da matéria seca. Os demais ingredientes utilizados foram caroço de algodão, farelo de algaroba, uréia, sulfato de amônia e suplemento vitamínico e mineral. O fornecimento do suplemento foi efetuado uma vez ao dia, às 8:00 horas da manhã. A quantidade fornecida foi ajustada diariamente em função do consumo evitando sobras superiores a $20 \%$ da quantidade fornecida. Os concentrados utilizados foram isoenergéticos, formulados para atingir $72 \%$ de nutrientes digestíveis totais (NDT) e 20, 30, 40 e $50 \%$ de proteína bruta (PB), conforme o National Research Council - NRC (2007).

Foram utilizados 36 ovinos, machos, nove animais por tratamento, castrados, sem padrão racial definido com peso vivo inicial médio de $18 \mathrm{~kg}$ distribuídos em quatro grupos e mantidos em pastejo direto. O período experimental estendeu-se de outubro a dezembro de 2007 , com duração de 70 dias. A pesagem dos animais foi efetuada a cada oito dias sempre no início da manhã.

$\mathrm{Na}$ véspera do abate, os ovinos foram pesados e mantidos em jejum alimentar por 16 horas. O abate dos animais foi realizado no abatedouro municipal de Petrolina/PE. Após o abate os animais foram eviscerados. Posteriormente, as carcaças foram pesadas e a partir desse peso foi calculado o rendimento de carcaça. O rendimento de carcaça quente foi calculado de acordo com a equação: RCQ $(\%)=$ $(\mathrm{PCQ} / \mathrm{PCA}) \times 100$, sendo RCQ $=$ rendimento de carcaça quente, $\mathrm{PCQ}=$ peso de carcaça quente e PCA = peso corporal de abate. A meia carcaça direita foi secionada em quatro partes, sendo: pernil, paleta, carré, e costela.

O delineamento experimental adotado foi o inteiramente casualizado com nove repetições por tratamento. As análises estatísticas foram realizadas por meio do Statistycal Analyses System - SAS (1999), considerando 5\% $(\mathrm{P}<0,05)$ como nível significativo pelo teste de Tukey.

\section{Resultados e Discussão}

Os teores de uréia nos concentrados não influenciaram $(\mathrm{P}>0,05)$ os pesos e rendimentos de carcaça quente e fria (Tabela 1). Os resultados observados podem ser justificados pela ausência de efeitos significativos dos teores de uréia nos suplementos sobre o desempenho produtivo dos animais o que refletiu nos semelhantes pesos corporais finais e sobre os parâmetros de carcaças avaliados.

Os resultados observados estão de acordo aos reportados por Souza et al. (2004) que avaliaram o ganho de peso, características de carcaça e dos demais componentes corporais de cordeiros confinados, alimentados com doses crescentes de uréia na ração e observaram semelhantes pesos, rendimentos e conformação das carcaças para os animais suplementados. Nesse estudo os teores de uréia na ração variaram de 0 a $1,2 \%$.

Tabela 1. Pesos e rendimentos de carcaça quente e fria de ovinos alimentados com suplementos múltiplos contendo teores crescentes de uréia

\begin{tabular}{lcccccc}
\hline \multirow{2}{*}{ Componentes } & \multicolumn{4}{c}{ Teor de uréia no suplemento (\%) } & \multirow{2}{*}{ EPM } & \multirow{2}{*}{ P } \\
\cline { 2 - 5 } & 5 & 8 & 11 & 14 & & \\
\hline Peso de carcaça quente, $\mathrm{kg}$ & 9,56 & 9,25 & 9,56 & 9,59 & 0,29 & 0,82 \\
Peso de carcaça fria, kg & 7,45 & 7,08 & 6,89 & 7,37 & 0,16 & 0,63 \\
Rendimento de carcaça quente, $\%$ & 44,50 & 43,89 & 44,17 & 44,46 & 4,14 & 0,99 \\
Rendimento de carcaça fria, \% & 34,56 & 33,61 & 32,05 & 34,11 & 1,53 & 0,66 \\
\hline
\end{tabular}

$\mathrm{EPM}=$ erro padrão da média, $\mathrm{P}=$ probabilidade.

Os pesos e rendimentos de cortes cárneos comerciais (pernil, paleta, costela e carré) não foram afetados $(\mathrm{P}>0,05)$ pelos crescentes teores de uréia nos suplementos concentrados (Tabela 2). Esses resultados podem ser justificados pela ausência de respostas dos suplementos sobre os pesos e rendimentos de carcaça. No estudo conduzido por Souza et al. (2004) também não foram encontradas diferenças significativas para pesos e rendimentos de cortes cárneos comerciais da carcaça de ovinos com o aumento nos teores de uréia nas rações. 
Tabela 2. Pesos e rendimentos de cortes cárneos comerciais da carcaça de ovinos criados em pastagens de capim Bufel recebendo suplementos múltiplos com teores crescentes de uréia

\begin{tabular}{lcccccc}
\hline \multirow{2}{*}{ Componentes } & \multicolumn{3}{c}{ Concentração de uréia no suplemento (\%) } & \multirow{2}{*}{ EPM } & P \\
\cline { 2 - 5 } & 5 & 8 & 11 & 14 & & \\
\hline Pernil, kg & 1.193 & 1.217 & 1.299 & 1.358 & 64 & 0,29 \\
Pernil, \% da meia carcaça & 33,70 & 33,99 & 37,25 & 38,55 & 1,23 & 0,38 \\
Paleta, kg & 0.613 & 0.554 & 0.679 & 0.650 & 53 & 0,39 \\
Paleta, \% da meia carcaça & 17,20 & 15,61 & 19,41 & 18,32 & 1,58 & 0,38 \\
Carré, kg & 1.027 & 1.010 & 1.151 & 1.063 & 49,50 & 0,20 \\
Carré, \% da meia carcaça & 28,88 & 28,14 & 32,87 & 30,06 & 1,57 & 0,22 \\
Costela, kg & 0.263 & 0.280 & 0.300 & 0.262 & 13,25 & 0,15 \\
Costela, \% da meia carcaça & 7,42 & 7,77 & 8,65 & 7,38 & 0,48 & 0,20 \\
EPM = erro padrão da média, $\mathrm{P}=$ probabilidade. & & & & &
\end{tabular}

\section{Conclusões}

Os diferentes teores de uréia utilizados nos suplementos múltiplos para os ovinos criados em pastagens de capim Bufel não afetaram as características de carcaça e os pesos e rendimentos de cortes cárneos comerciais.

\section{Literatura citada}

DOVE, H. The ruminant, the rumen and the pasture resource: nutrient interactions in grazing animal. In: HODGSON, J.; JILLIUS, A.W. (Eds.) The ecology and management in grazing systems. 2.ed. London: CAB International, 1996. p.219-246.

NATIONAL RESEARCH COUNCIL. Nutrient requeriments of small ruminants. 7thed. Washington: National Academic Press, 2007. 408 p.

SAS INSTITUTE. SAS STAT user's guide : version 6.4. Cary, 1999.

SILVA, S. C. da. Understanding the dynamics of herbage accumulation in tropical grass species: the basis for planning efficient grazing management practices. In: GRASSLAND ECOPHYSIOLOGY AND GRAZING ECOLOGY, 2., Anais... Curitiba, 2004. CD ROM.

SOUZA, P.P.S.de.; SIQUEIRA, E.R.de.; MAESTÁ, S.A. Ganho de peso, características de carcaça e dos demais componentes corporais de cordeiros confinados, alimentados com distintos teores de uréia.

Ciência Rural, v.34, n.4, p.1185-1190, 2004. 